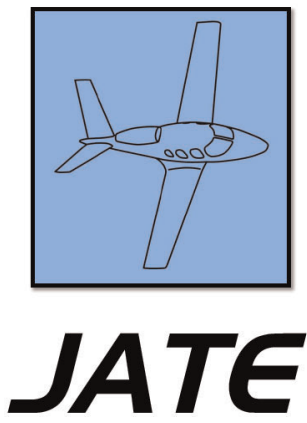

Journal of Aviation Technology and Engineering 9:1 (2020) 16-31

\title{
Pilot Source Study 2018: Five Years after the FOQ Rule-New-Hire First Officer Backgrounds and their Performance in US Regional Airline Training
}

\author{
Guy M. Smith \\ Aviation Accreditation Board International (AABI) \\ MaryJo O. Smith \\ Ypsilon Associates \\ Troy E. Techau \\ Windrose Aviation \\ Michelle P. Hight \\ Embry-Riddle Aeronautical University (Prescott)
}

\begin{abstract}
After the Pilot Source Study (PSS) 2015 was published, there was concern that the data were collected too soon after the First Officer Qualification Rule compliance date. The Collaborative Research Committee of the Aviation Accreditation Board International (AABI) voted to undertake the PSS 2018 to determine whether the results of the PSS 2015 were still valid. In fall 2018, five research teams collected 9,776 pilot records from five regional airlines and analyzed these data. In the PSS 2018, the criteria for success were: $\geqslant 90 \%$ completions and $\leq 1$ extra training event. In rank order, the following pilots were most successful in regional airline initial training: (1) pilots who had an undergraduate GPA of 3.3 or higher, (2) pilots who graduated from college within 5 years of their hire date, (3) pilots who had either a military R-ATP (750 hours) or an institutional R-ATP (1,000 hours), (4) pilots who graduated from an AABI-accredited flight program, (5) pilots who had 1,500 or fewer total flight hours, (6) pilots who had a bachelor degree. In addition to these variables, multivariate analysis showed that the following variables provide additional prediction and classification for success: age, younger; flight instructor, yes; military pilot, yes; previous FAA failures, fewer. All four PSSs (2010, 2012, 2015, and 2018) have substantiated the 2010 ANPRM statement: “...experience is not measured in flight time alone”.

Keywords: Pilot Source Study, PSS, Public Law 111-216, FOQ Rule, aviation training, pilot certification, Advanced Qualification Program, AQP, first officer, pilot training, airline pilot, new-hire pilot, flight hours, Aviation Accreditation Board International, AABI, CFI, flight instructor, ATP, R-ATP, initial operating experience, IOE
\end{abstract}




\section{Introduction}

On February 12, 2009, Colgan Air Flight 3407 impacted terrain while flying in icing conditions on approach to Buffalo, New York (National Transportation Safety Board, 2010). In the aftermath of the accident, training requirements for air carrier pilots in the USA underwent major changes; most notably, Public Law (PL) 111-216 (Airline Safety and Federal Aviation Administration Extension Act of 2010) mandated that air carrier first officers must have an Airline Transport Pilot (ATP) certificate that requires pilots be at least 23 years old and to have at least 1,500 total flight hours. Prior to PL 111-216, a typical airline first officer had approximately 300 total flight hours (Brady, 2015). During the rulemaking process, aviation education advocacy groups successfully persuaded the Federal Aviation Administration (FAA) to develop the Restricted ATP (R-ATP) certificate that reduces the age and flight hour requirements for military pilots and qualified graduates from specifically approved collegiate flight degree programs (FAA, 2013). The Military R-ATP includes military pilots with at least 750 total flight hours. The Institutional Authority R-ATP includes graduates holding a bachelor's degree with an aviation major and at least 1,000 total flight hours or graduates holding an associate's degree with an aviation major and at least 1,250 total flight hours (FAA, 2013).

The present research article is a continuation of the Pilot Source Study (PSS) that began in 2010 to quantify the background and performance characteristics of pilots being hired by regional airlines. The PSS is in its fourth iteration: PSS 2018. Data for the four studies were collected in 2010, 2012, 2015 , and the present study in 2018. The pilots included in the present study were hired by five US regional airlines between the summer of 2015 and the fall of 2018 .

The enduring value of the PSS is the longitudinal nature of the series. Collectively, the studies provide insights into how changes in pilot training over the past 14 years are reflected in both the Background and Performance variables of the pilots entering the regional airline workforce. The PSS series is not about regional airline training itself; it is an investigation of changes in pilots' backgrounds and their impact on pilots' performance during training at a regional airline as a result of PL 111-216 (Airline Safety and FAA Extension Act of 2010) and the subsequent 2013 First Officer Qualification (FOQ) Rule (FAA, 2013). To some degree, the PSS permits comparison of pilots entering the regional airline workforce throughout the major changes of the past 14 years, even though pilots in the present study completed a training footprint that was different from previous studies.

The PSS is sometimes misunderstood as a pilot "supply" study. The PSS population is the cadre of pilots who were hired by a regional airline; i.e., the PSS population was extracted from the pilot supply. Therefore, the population of a pilot supply study - at any given time-includes the cadre of pilots eligible for hire; when a pilot is hired, he/she is automatically removed from the pilot supply. Since the population of the PSS is independent of the pilot supply, this study cannot draw conclusions about pilot supply or pilot shortages.

\section{Review of the Literature}

The changes in pilot hiring, resulting from the 2010 passage of PL 111-216 (Airline Safety and FAA Extension Act of 2010) and the subsequent FOQ Rule (FAA, 2013), primarily affected US regional airlines and their ability to hire first officers. Regional airlines provide critical infrastructure: "63\% of U.S. airports with scheduled passenger air service get their ONLY source of air service from regional airlines" and " $41 \%$ of scheduled passenger departures were operated by U.S. regional airlines" (Regional Airline Association, 2019, p. 16). "Regional airlines serve $93 \%$ of the nation's airports receiving scheduled passenger service" while "Major airlines directly serve only 37\% of the nation's airports receiving scheduled passenger service" (p. 20).

During the rule-making process that led to PL 111-216 (Airline Safety and FAA Extension Act of 2010), the FAA issued an Advance Notice of Proposed Rulemaking (ANPRM) that stated, "The FAA believes that, although the flight hours required to qualify for an ATP certificate can benefit pilots, experience is not measured in flight time alone. Other factors, such as certain types of academic training, practical training/experience, and experience in a crew environment, are also important" (FAA, 2010, para. 3). The 2010 PSS was established to analyze the "other factors" that may contribute to a pilot's success in the regional airlines. Repeated in 2012, 2015, and 2018, the research evolved to become a longitudinal view of the underlying Background variables that significantly increase pilots' probability to successfully complete their airline training and become Part 121 first officers. The PSS series is unique in that the data spans seven years (2005-2011) prior to the law change and six years (2013-2018) after the law change.

Training programs for new-hire air carrier pilots also evolved after the Colgan Air accident. In 2017, the FAA updated its guidance regarding operation of an Advanced Qualification Program (AQP) for air carriers operating under $14 \mathrm{CFR} \S 121$ and 135. AQP guidance is promulgated in Advisory Circular 120-54A (FAA, 2017) and is based on requirements found in 14 CFR $\$ 121$ (Operating Requirements, 2015). Advisory Circular 120-54A states that AQP offers a "systematic methodology for developing the content of training programs for air carrier crewmembers" and "replaces programmed hours with proficiencybased training and evaluation" (FAA, 2017, p. 1). AQP incorporates scenario-based training as a means to train pilots for operation in actual flight conditions they will likely experience during air carrier operations, supports evaluation 
of pilots as air crew members instead of solely as individuals, improves standardization, and integrates crew resource management skills into training activities (FAA, 2017).

The 2010 PSS (Smith, Bjerke, NewMyer, Niemczyk, \& Hamilton, 2010) collected data for 2,187 pilots at six regional airlines hired between 2005 and 2009. The researchers found that the highest level of degree (associate, bachelor, or none), previous military experience, and previous corporate pilot experience had no significant influence on the number of extra training events. The 2010 PSS significant results were:

- Certificated Flight Instructors required fewer extra training events and had fewer non-completions than pilots who were not flight instructors.

- Graduates from Aviation Accreditation Board International (AABI)-accredited flight degree programs required fewer extra training events and had fewer non-completions than graduates of other programs.

- Pilots trained in collegiate flight programs required fewer extra training events and had fewer noncompletions than pilots trained in non-college Part 141/142 or Part 61 flight training programs.

- Pilots who graduated with an aviation-related degree required fewer extra training events and had fewer non-completions than graduates with other degrees.

- Pilots with 501-1,000 flight hours required fewer extra training events and had fewer non-completions than pilots with $0-500,1,001-1,500$, or greater than 1,500 flight hours.

The 2012 PSS (Smith et al., 2013) utilized the same research design as the 2010 PSS, reporting on data for 4,024 pilots hired between 2005 and 2011 at seven additional regional airlines. The researchers concluded that graduating from an AABI-accredited flight degree program or holding a Flight Instructor certificate had no significant effect on extra training events, a departure from the 2010 PSS. In addition, Pilot Certificates (Commercial or ATP) had no significant effect on extra training events. Smith et al. (2013) found the following significant results:

- Pilots with a college degree required fewer extra training events than pilots without an associate's or bachelor's degree.

- Pilots with an aviation-related degree required fewer extra training events and had fewer non-completions than graduates of other programs (also significant in 2010).

- Pilots with flight training from either military, college, or non-college Part 141/142 flight programs required fewer extra training events than pilots trained in noncollege Part 61 training programs (also significant in 2010).

- Pilots with prior airline experience required fewer extra training events.
- Pilots with 501-1,000 flight hours required more extra training events (contrary results in 2010); pilots with 1,001-1,500 flight hours required fewer extra training events and had fewer non-completions.

The 2015 PSS (Bjerke et al., 2016; Smith, G. et al., 2016; Smith, M. O. et al., 2017) was a population study that collected 6,734 pilot records from 19 Part 121 airlines. The 2015 PSS pilots were hired after August 1, 2013, the compliance date of the FOQ Rule (FAA, 2013), through the summer of 2015. As the post-law data were collected after the effective date of the FOQ Rule, the 2015 PSS provided a comparison with the two pre-law studies (Smith et al., 2010, 2013). The researchers found no significant differences between pre- and post-law regional pilots for their level of education. Significantly fewer pilots were hired with aviation-related degrees or AABI-accredited flight degrees. These results reflected the increase in secondcareer pilots hired, the increase in military pilots hired, and the overall increase in airline hiring. The 2015 PSS concluded that:

- Pilots with fewer than four years since graduation had fewer non-completions and fewer extra training events.

- Pilots with 1,500 or fewer total flight hours had fewer non-completions and fewer extra training events (also significant in 2010 and 2012).

- Pilots with AABI-accredited flight degrees had fewer non-completions and fewer extra training events (also significant in 2010).

- Pilots with an Institutional Authority R-ATP (1,000 hours or 1,250 hours) had fewer non-completions and fewer extra training events (also significant in 2010 and 2012).

- Pilots with an aviation-related degree had fewer noncompletions and fewer extra training events (also significant in 2010 and 2012).

- Pilots with a bachelor's degree had fewer noncompletions and fewer extra training events (also significant in 2012).

Besides the PSS series, two additional research studies examined pilot hiring and training. Shane (2016) analyzed application and training data for pilots hired in 2015 at one regional airline. Shane concluded, "Pilots who have recently flown and have been in a structured training environment tend to perform better in training. Likewise, pilots who are actively exercising their flying skills, have recently been employed as pilots and have experience flying in a similar type of flying operation also tend to perform better in training" (p. 95). Lutte (2018) conducted a qualitative case study examining pilot supply at eight regional airlines. Lutte concluded that pilot pay had significantly increased at the regional airlines, positively impacting the ability of the airlines to hire the number of pilots required. Secondly, regional airlines were concerned about being able to sustain 
their ability to hire enough pilots. Factors other than pay were important to the pilots being hired, including location of pilot bases, company culture, commuter policies, and the ability for a pilot to transition to a major airline carrier.

\section{Research Questions}

For the 2018 PSS, the research questions were:

- How do new-hire US regional airline pilots perform in airline training, based on their backgrounds and flight experience?

- How do the results of the 2018 PSS compare with the results of the 2015 PSS?

\section{Data Collection}

The AABI Collaborative Research Committee defined the population for the 2018 PSS as pilots hired by US regional airlines after the data collection date of the 2015 PSS in order to avoid duplication of pilots. The airline selection process was different from that of the 2015 study due to limited resources, i.e., time, money, and data collection personnel, and the increased number of pilots hired. Resources were not available for another population study; therefore, the researchers asked the Regional Airline Association to identify the top ten airlines that hired the most pilots between 2015 and 2018. The five regional airlines with the most pilots hired provided data for this study: Endeavor Air, Envoy Air, PSA Airlines, Republic Airways, and SkyWest Airlines.

The first step in the data collection process was to contact senior management at the airlines (President, VP of Operations, etc.) to request permission for a data collection team to collect new-hire pilot Background data from human resources (HR) and/or recruiting department pilot records and Performance data from the training department or AQP pilot records. Two important documents accompanied these requests: (a) a non-disclosure agreement that the data would be de-identified and would be used only for the 2018 PSS; and (b) a data collection protocol to ensure data collection procedures were equivalent at all five airlines. From September to November 2018, teams of five or six data collectors visited each of the five airlines for approximately one week to collect data. After the data collection was complete, the five de-identified datasets were combined into a single master file: 2018 PSS Dataset. The 2018 PSS Dataset consisted of 9,776 records of regional airline pilots hired in the three-year period from summer 2015 to fall 2018.

\section{Limitations of the Study}

All PSS data came from airline records made available to the researchers from the airlines' HR, recruiting, and training departments. Pilots were not interviewed, logbooks were not examined, prior employers were not contacted, and the airline data were not corroborated. Therefore, the PSS data were only as valid as the airline records; the data collectors did not validate any airline records.

Performance data were limited in specificity; besides recording completion dates for the elements of a training program, most airlines recorded when a pilot required an extra training event that was beyond the requirements of the current training footprint. None of the airlines recorded scalar scores for tests, evaluations, or validations; only nominal data were recorded (completions, incompletions, and extra training events).

Several training managers reported that their training programs evolved since August 1, 2013; the training footprint for new-hire pilots continues to lengthen. Since the PSS is a study of individual pilots, any modification of the training footprint for all pilots was not recorded as "extra training" for any individual pilot.

The Background data collected from HR and recruiting records have many limitations. Data collection was delimited by the number of records, the number of data collectors, the timeframe available, and how the data were accessed by the data collection team. The Background data were self-reported by pilots in paper forms or electronic media: resumes, cover letters, transcripts, and electronic applications such as: Airline Apps (www.airlineapps.com), iCIMS (www.icims.com), or other airline-designed forms.

The main limitation of collected Background data was the uncertain accuracy of the self-reported flight hours. The data collectors tried to establish an accurate record of flight hours accrued by a pilot's hire date. The flight hour data were self-reported by the pilots. Flight hour data were reported at the time of application, which could be weeks, months, or even years before the pilot's hire date. Even if an airline archived the application data on the pilot's hire date, the airline had no assurance that pilots updated their application data at or near their date of hire. Another limitation was accuracy of the self-reported data; some pilots were meticulous in recording their data, particularly logbook hours; other pilots reported estimates or approximations; and some pilots skipped important data fields altogether. Airlines validate logged flight hours to confirm a pilot's eligibility for employment as a Part 121 first officer. In addition, one airline recorded the validated logbook total flight hours in a spreadsheet that was used during data collection.

Several variables were particularly troublesome because of pilots' inconsistencies and/or lack of detail provided for several flight hour categories. Some recency data (flight hours in the last six months or in the last year) appeared to be invalid, and many pilots did not report recency data. Instrument flight hours reported often appeared to be composed of a combination of: actual instrument hours, simulated instrument hours, both actual and simulated 
instrument hours, or even hours on an IFR flight plan. Dual-given hours, an important data point used to determine the experience of a flight instructor, were often missing, even for pilots whose predominant employment was flight instructor.

Undergraduate GPA was under-reported because GPA was often reported in a non-standardized resume format. Thus, pilots with higher GPAs seemed more likely to report their GPAs than pilots with lower GPAs.

\section{Descriptive Statistics}

\section{Background Data}

To analyze the data, the researchers separated Background data into categorical or continuous variables. The variables were further classified as: demographics (or social statistics), educational experience, employment history, or flight hours.

Table 1 describes the categorical variables in the Background dataset: two demographic variables, four education variables, and six employment variables. Some categorical variables are self-explanatory; other variables are defined.

To be classified as an AABI-accredited flight degree program graduate, a pilot must have graduated from one of the universities listed as an accredited program on the official website of AABI (http://www.aabi.aero/) and must have graduated with a degree accredited under AABI's program criteria for flight education, as defined in AABI Form 201, §5.5 (AABI, 2019).

The criterion for aviation degree includes any degree from any college or university with an aviation or aviationrelated title, e.g., aviation management, unmanned aerial systems, air traffic control, etc. Aviation degree also includes pilots classified as AABI-accredited flight degree program graduates.

Data collectors determined predominant employment through an assessment of each pilot's previous career after reviewing his/her HR record. For example, the predominant employment of a military pilot could be Part 135, if the pilot was flying for a Part 135 air carrier after separating from the military.

Previous FAA failures, a categorical variable, were recorded in $75 \%$ of the records. Military pilots usually reported zero previous FAA failures.

Type ATP recorded a pilot's eligibility for the ATP certificate; it does not indicate the total flight hours that a pilot accrued before employment with the airline. For example, a former military pilot would be categorized as eligible for the Military R-ATP (750 hours) certificate even though that pilot accrued hundreds or thousands of flight hours above the 750-hour minimum at his/her date of hire.

The continuous variables include one demographic variable, two education variables, and twelve flight hour variables. Table 2 describes the continuous variables in the Background dataset.

Age at date of hire was derived by subtracting the airline hire date from the pilot's birth date. Age at date of hire emphasizes the age gap resulting from PL 111-216 (Airline Safety and FAA Extension Act of 2010) and the FOQ Rule (FAA, 2013). Prior to PL 111-216, pilots could be hired as a Part 121 first officer after attaining their commercial pilot certificates that has a minimum age requirement of 18 years. The overall average age at date of hire was 34, though the Institutional Authority R-ATP (1,000 hours and 1,250 hours) pilots were younger with a median age of 25 years and an average age of 28 years.

Table 1

Categorical background variables-descriptive statistics.

\begin{tabular}{|c|c|c|c|}
\hline Background variable & Type of variable & Count $(\%$ of 9,776$)$ & Description \\
\hline Gender & Demographic & $9,735(99 \%)$ & $94 \%$ male I $6 \%$ female \\
\hline Year hired & Demographic & $9,733(99 \%)$ & $\begin{array}{l}10 \% \text { in } 2015 \text { | } 26.5 \% \text { in } 2016 \\
37 \% \text { in } 2017 \mid 26.5 \% \text { in } 2018\end{array}$ \\
\hline Highest level of degree & Education & $9,613(98 \%)$ & $\begin{array}{l}18 \% \text { high school I } 9 \% \text { associate } \\
61.5 \% \text { bachelor I } 10.5 \% \text { masters } 1 \% \text { doctorate }\end{array}$ \\
\hline $\begin{array}{l}\text { AABI-accredited flight degree } \\
\text { program graduate }\end{array}$ & Education & $7,908(81 \%)$ & $27 \%$ yes I $73 \%$ no \\
\hline Aviation degree & Education & $7,907(81 \%)$ & $62 \%$ yes । $38 \%$ no \\
\hline Previous FAA failures & Education & $7,366(75 \%)$ & $\begin{array}{c}45.5 \% \text { none I } 33 \% \text { one I } 14 \% \text { two } \\
7.5 \% \text { more than two }\end{array}$ \\
\hline Flight instructor & Employment & $8,704(89 \%)$ & $80 \%$ yes I $20 \%$ no \\
\hline Foreign pilot license & Employment & $9,776(100 \%)$ & $2 \%$ Foreign | $98 \%$ US \\
\hline Military pilot & Employment & $9,776(100 \%)$ & $20 \%$ military | $80 \%$ civilian \\
\hline Rotor/helicopter pilot & Employment & $9,776(100 \%)$ & $8 \%$ rotor $\mid 92 \%$ non-rotor \\
\hline Predominant employment & Employment & $9,483(97 \%)$ & $\begin{array}{c}42 \% \text { flight instructor I } 16 \% \text { Part } 135 \\
\text { 14\% US military I 13\% Part } 121 \\
9 \% \text { Part } 91 \text { । 3\% non-aviation } \\
2 \% \text { aviation non-pilot I } 1 \% \text { other pilot }\end{array}$ \\
\hline Type ATP & Employment & $9,654(99 \%)$ & $\begin{array}{c}68 \% \text { ATP }(1,500) \mid 4 \% \text { R-ATP }(1,250) \\
18 \% \text { R-ATP }(1,000) \mid 10 \% \text { R-ATP }(750)\end{array}$ \\
\hline
\end{tabular}


Table 2

Continuous background variables-descriptive statistics.

\begin{tabular}{|c|c|c|c|c|}
\hline Background variable & Variable type & Count (\% of 9,776$)$ & Mean & Standard deviation \\
\hline Age at date of hire & Demographic & $9,755(99.8 \%)$ & 34.0 & 9.9 \\
\hline Undergraduate GPA & Education & $4,369(44.7 \%)$ & 3.4 & 0.4 \\
\hline Years between graduation and hire & Education & $7,488(76.6 \%)$ & 8.3 & 8.4 \\
\hline Total flight hours ${ }^{\mathrm{a}}$ & Flight hours & $9,753(99.8 \%)$ & 2502.0 & 2315.0 \\
\hline Instrument hours & Flight hours & $9,094(93.0 \%)$ & 303.0 & 563.0 \\
\hline PIC hours & Flight hours & $7,583(77.6 \%)$ & 1696.0 & 1719.0 \\
\hline SIC hours & Flight hours & $2,664(27.3 \%)$ & 741.0 & 1181.0 \\
\hline Multi-engine hours & Flight hours & $9,206(94.2 \%)$ & 1081.0 & 2002.0 \\
\hline Turbine hours & Flight hours & $4,002(40.9 \%)$ & 1738.0 & 2236.0 \\
\hline Night hours & Flight hours & $6,244(63.9 \%)$ & 331.0 & 636.0 \\
\hline $\mathrm{XC}$ hours & Flight hours & $8,988(91.9 \%)$ & 1328.0 & 1958.0 \\
\hline Rotor hours & Flight hours & $752(7.7 \%)$ & 1447.0 & 1618.0 \\
\hline Dual given (instructor) hours & Flight hours & $2,785(28.5 \%)$ & 847.0 & 807.0 \\
\hline Recency hours (last 6 months) & Flight hours & $1,688(17.3 \%)$ & 497.0 & 280.0 \\
\hline Recency hours (last year) & Flight hours & $2,429(24.8 \%)$ & 475.0 & 327.0 \\
\hline
\end{tabular}

${ }^{a}$ Total flight hours were the self-reported number of flight hours: it was not a summation of the various types of flight hours. Total flight hours were the only flight hour variable analyzed in the univariate analyses.

Years between graduation and hire was derived by subtracting the airline hire date from the pilot's undergraduate graduation date. The relatively large average years between graduation and hire (8.3 years) also emphasized another consequence of PL 111-216 (Airline Safety and FAA Extension Act of 2010) and the FOQ Rule (FAA, 2013). For pilots with high school as their highest level of degree, their undergraduate graduation date did not exist; therefore, these pilots had no data for years between graduation and hire.

Total flight hours is the central Background variable. The FOQ Rule (FAA, 2013) determines pilot eligibility for employment as a Part 121 first officer by total flight hours.

\section{Performance Data}

For analyses, the Performance data were separated into categorical variables and continuous variables. Some airlines conduct their initial pilot training under the AQP Advisory Circular guidelines; other airlines train under the traditional 14 CFR Part 121, Subparts N and O (Operating Requirements, 2015). The categorical training variables are a combination of the two types of training as shown in Table 3.

Table 4 describes the categorical variables in the Performance data. Whenever a pilot required a repeat, extra validation (AQP), or extra test (traditional), one extra training event was recorded. At the discretion of the instructor, some pilots required extra training events to prepare them for a validation or test; each extra training event was counted as one extra training event. Total extra training events was the sum of all extra training events that a pilot needed from beginning his/her indoctrination class until completing his/her training program.

At the time of data collection at an airline, each pilot's status was recorded as: on leave (mostly for military duty), in training (not yet completed), terminated in training (withdrew from training), or completed training (released for line flying). For $55 \%$ of the terminated pilots, the records showed the segment of training where a pilot withdrew or was withdrawn from training (classroom, simulator, aircraft, or miscellaneous). Reason for termination (performance or resignation) was also recorded for $78 \%$ of the withdrawn pilots; however, not all recorded reasons were considered valid because airlines sometimes offered the pilot an option to resign instead of being terminated for performance reasons.

After completing their ground and simulator training, the pilots continue their training with initial operating experience (IOE), flying revenue flights in an aircraft as secondin-command under the supervision of a Check Captain. The FAA requires a minimum of 25 IOE hours. IOE hours may be reduced for takeoffs and landings accomplished under specific criteria (Operating Requirements, 2015). None of the airlines in this study utilized these allowed hour reductions for their new-hire first officers.

IOE hours may be extended beyond the minimum 25 hours for performance reasons or, more commonly, for non-performance-related reasons, e.g., scheduling requirements, length of a flight, meeting other requirements of IOE, etc. In order to derive a variable for extended IOE that was performance-related, an IOE Z-score or standard IOE score was calculated for each airline, allowing dissimilar IOE data from the five airlines to be combined into one dataset. The airline training managers agree that a pilot who required more than one standard deviation above their airline mean IOE $Z$-score needed performance-related extended IOE. Table 5 defines the continuous Performance variables IOE hours and IOE $Z$-score.

\section{Univariate Analyses-Total Extra Training Events}

The univariate analyses tested the null hypothesis: no significant difference existed between the Performance 
Table 3

Derivation of categorical performance variables.

\begin{tabular}{lll}
\hline Derived Performance variable & AQP training variables & Traditional training variable \\
\hline Extra knowledge & Knowledge validation (KV) & Knowledge Test \\
Extra systems & Systems validation (SV) & Systems Test \\
Extra maneuvers & Maneuvers validation (MV) & Maneuvers Test \\
Extra procedures & Procedures validation (PV) & Procedures Test \\
Extra LOE/LOS/LOFT & Line-oriented evaluation (LOE) & Line-oriented simulation (LOS) or line-oriented \\
Extra training events & Discretionary extra training events & Discretionary extra training events (not checking events) \\
\end{tabular}

Table 4

Categorical performance variables-descriptive statistics.

\begin{tabular}{|c|c|c|}
\hline Performance variable & Count $(\%$ of 9,776$)$ & Description \\
\hline Total extra training events ${ }^{a}$ & $8,774(90 \%)$ & $55.3 \%$ none | $19.2 \%$ one | $10.6 \%$ two | $5.4 \%$ three | $9.5 \%$ more than three \\
\hline Extra knowledge & $7,753(79 \%)$ & $96.9 \%$ none | $2.9 \%$ one | $0.2 \%$ more than one \\
\hline Extra systems & $7,652(78 \%)$ & $90.5 \%$ none | $8.4 \%$ one | $1.1 \%$ more than one \\
\hline Extra maneuvers & $6,985(71 \%)$ & $95.3 \%$ none $13.0 \%$ one | $1.7 \%$ more than one \\
\hline Extra procedures & $5,860(60 \%)$ & $96.4 \%$ none $\mid 2.8 \%$ one $10.8 \%$ more than one \\
\hline Extra LOE/LOS & $5,346(55 \%)$ & $94.5 \%$ none $\mid 4.5 \%$ one | $1.0 \%$ more than one \\
\hline Extra training events & $7,137(73 \%)$ & $59.0 \%$ none | $16.0 \%$ one | $25.0 \%$ more than one \\
\hline Status $^{\mathrm{a}}$ & $9,776(100 \%)$ & $0.6 \%$ leave | $9.5 \%$ terminated in training | $12.3 \%$ in training $\mid 77.6 \%$ completed training \\
\hline When terminated & $926(9 \%)$ & $\begin{array}{l}26.2 \% \text { classroom [Indoc, Ground, KV, Systems, Oral] } \\
25.1 \% \text { simulator [MV, PV, Sim, LOE] } \\
4.2 \% \text { aircraft [IOE] } \\
44.5 \% \text { miscellaneous }[\mathrm{HR} \text {, training, not reported] }\end{array}$ \\
\hline Reason for termination & $926(9 \%)$ & $50.1 \%$ performance $\mid 28.5 \%$ resignation $\mid 21.4 \%$ not reported \\
\hline
\end{tabular}

${ }^{\text {a }}$ Total extra training events and status are the only dependent variables in this table that were analyzed in the univariate analyses.

Table 5

Continuous performance variables-descriptive statistics.

\begin{tabular}{|c|c|c|c|c|}
\hline Performance variable & Count (\% of 9,776 ) & Mean & Standard deviation & $>1$ Standard deviation \\
\hline IOE hours & $7,562(77 \%)$ & 38.1 & 13.0 & 51.1 \\
\hline IOE Z-score & $7,562(77 \%)$ & 0.0 & 1.0 & $965(9.87 \%)$ \\
\hline
\end{tabular}

variables: total extra training events, completion percentage, or extended IOE and the Background variables. For total extra training events, the univariate analyses included all pilots with data in both total extra training events and the Background variables $(N=9772)$.

\section{Gender}

A small subset of female pilots within the already small sample size of females (5.6\%) skewed the data. Therefore, the researchers considered the gender results to be spurious.

\section{Age at Date of Hire}

The one-way ANOVA showed significant differences in total extra training events based on age at date of hire $(N=8754 ; F(3,8752)=14.91, p<0.00)$. Younger pilots whose age at date of hire was $\leq 31$ required significantly fewer total extra training events (average $=1.03$ ).

\section{Highest Level of Degree}

The one-way ANOVA showed significant differences in total extra training events based on highest level of degree $(N=8621 ; F(4,8616)=11.78, p<0.00)$. Figure 1 shows the average total extra training events based on highest level of degree. Pilots with bachelor's degrees required significantly fewer total extra training events (average $=1.0$ ) compared to pilots with a high school diploma, master's degree, or doctoral degree. No significant difference existed in total extra training events between pilots with bachelor's degrees and pilots with associate's degrees.

\section{AABI-Accredited Flight Degree Program Graduate}

The one-way ANOVA showed significant differences in total extra training events based on AABI-accredited flight degree program graduates $(N=7106 ; F(1,7104)=23.66$, $p<0.00)$. AABI-accredited flight degree program 


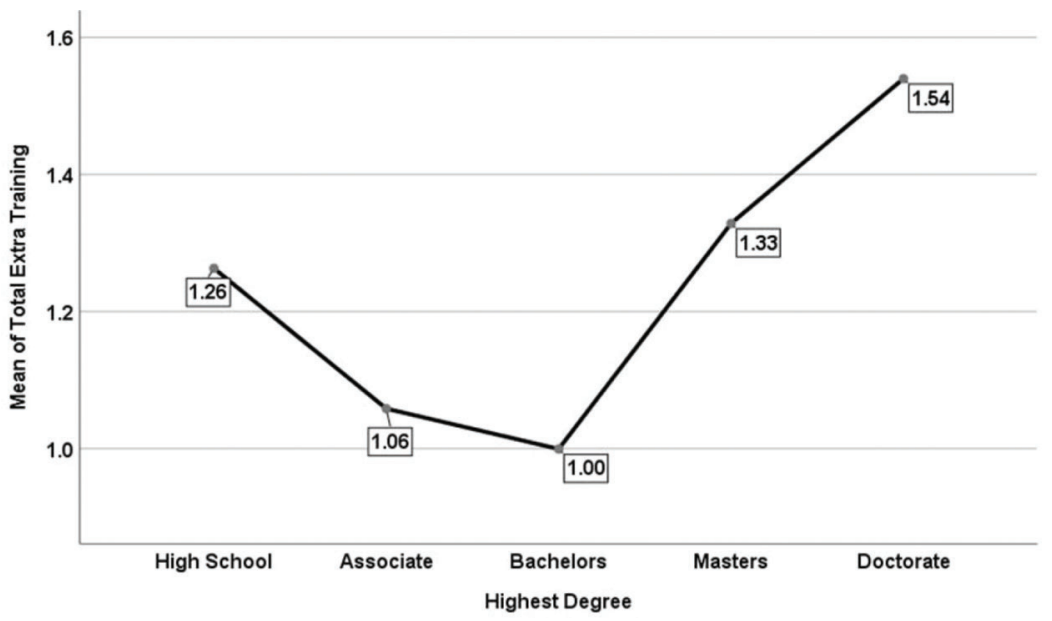

Figure 1. Total extra training events based on highest level of degree.

graduates required significantly fewer total extra training events (average $=0.89$ ).

\section{Aviation Graduate}

No difference existed in total extra training events based on aviation graduate.

\section{Undergraduate GPA}

The one-way ANOVA showed significant differences in total extra training events based on undergraduate GPA $(N=3986 ; F(3,3982)=7.05, p<0.00)$. Pilots with an undergraduate GPA of 3.3-3.8 required significantly fewer total extra training events (average $=0.81$ ). Pilots with an undergraduate GPA greater than 3.8 also required significantly fewer total extra training events (average = $0.76)$.

\section{Years between Graduation and Hire}

The one-way ANOVA showed significant differences in total extra training events based on years between graduation and hire $(N=6712 ; F(8,6703)=17.81, p<0.00)$. Figure 2 shows the average total extra training events based on years between graduation and hire. The categories of $0-5$ years and $6-10$ years from undergraduate graduation date to the date of hire required significantly fewer total extra training events.

\section{Flight Instructor}

The one-way ANOVA showed significant differences in total extra training events based on flight instructor certification $(N=7839 ; F(1,7837)=14.80, p<0.00)$. Pilots with Flight Instructor certificates required significantly fewer total extra training events (average $=1.09$ ).

\section{Military Pilot}

The one-way ANOVA showed significant differences in total extra training events for former military pilots $(N=8774 ; F(1,8772)=30.15, p<0.00)$. Former military pilots required significantly fewer total extra training events (average $=0.89$ ).

\section{Rotor/Helicopter Pilot}

The one-way ANOVA showed significant differences in total extra training events for former rotor/helicopter pilots $(N=8774 ; F(1,8772)=7.26, p=0.007)$. Former rotor/ helicopter pilots required significantly fewer total extra training events (average $=0.93$ ).

\section{Predominant Employment}

The one-way ANOVA showed significant differences in total extra training events based on predominant employment $(N=8550 ; F(7,8542)=7.06, p<0.00)$. Pilots whose predominant employment was Part 121 required significantly fewer total extra training events (average $=0.86$ ). Pilots whose predominant employment was Part 135 require significantly more total extra training events (average $=1.13$ ). Pilots whose predominant employment was Part 91 also required significantly more total extra training events (average $=1.32$ ).

\section{Reported Failed FAA Check-Rides}

The one-way ANOVA showed significant differences in total extra training events based on reported failed FAA check-rides $(N=8550 ; F(7,8542)=7.06, p<0.00)$. Pilots with two or more reported failed FAA check-rides required significantly more total extra training events (average $=1.31)$. 


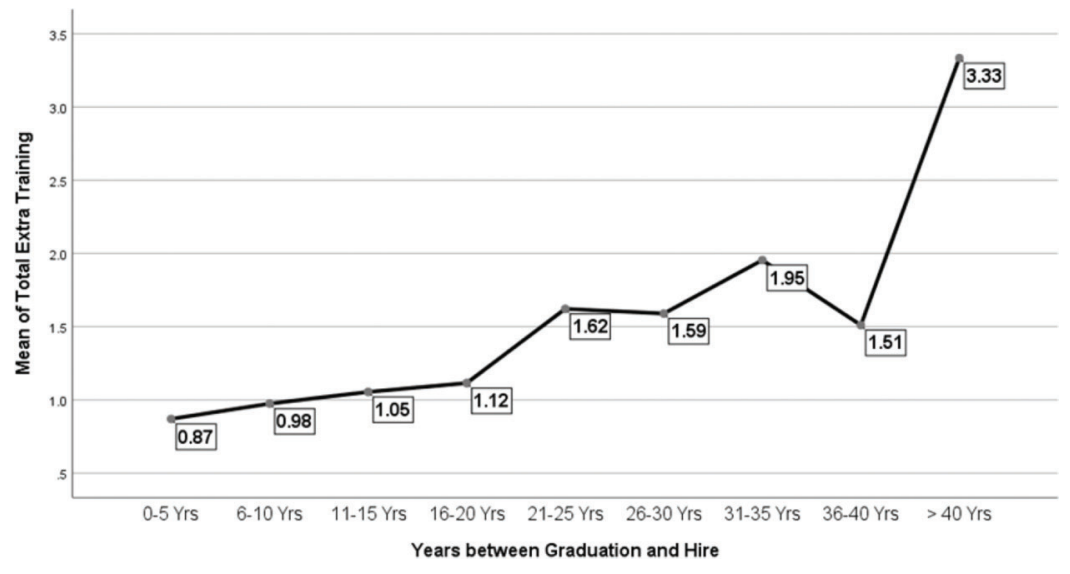

Figure 2. Total extra training events based on years between graduation and hire.

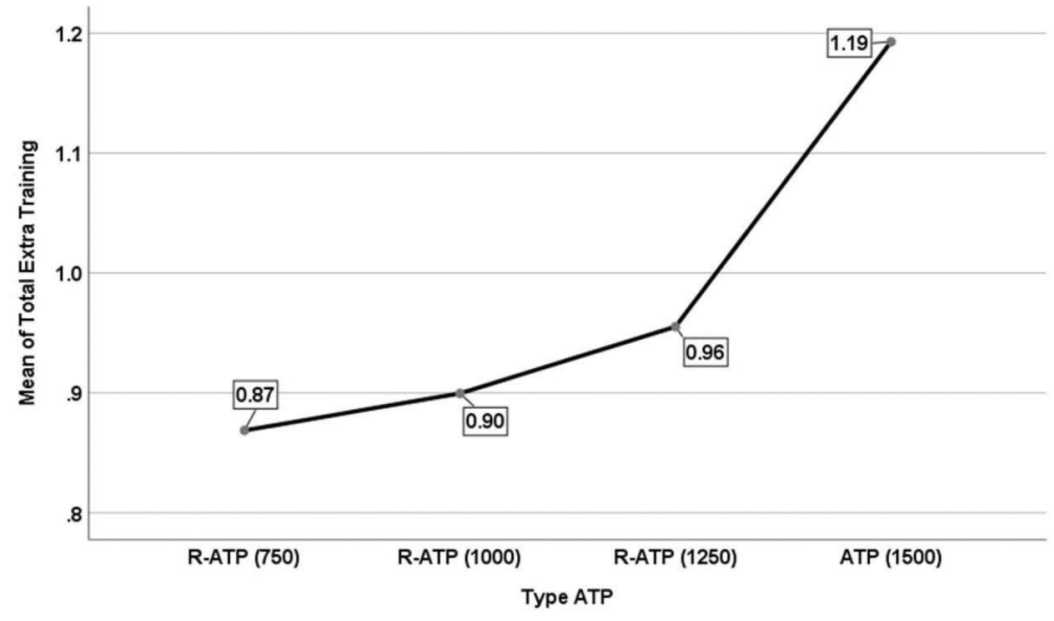

Figure 3. Total extra training events based on type ATP.

Type ATP

The one-way ANOVA showed significant differences in total extra training events based on type ATP $(N=8665$; $F(3,8661)=16.39, p<0.00)$. Figure 3 shows average total extra training events based on type ATP. All R-ATP levels required significantly fewer total extra training events.

\section{Total Flight Hours}

The one-way ANOVA showed significant differences in total extra training events based on total flight hours $(N=8754 ; F(3,8750)=65.24, p<0.00)$. Figure 4 shows the average total extra training events based on total flight hours. The categories 750-999 and 1,000-1,500 total flight hours required significantly fewer total extra training events.

\section{Recency Hours-Last 6 Months}

No difference existed in total extra training events based on recency hours in the last 6 months.

\section{Recency Hours-Last Year}

No difference existed in total extra training events based on recency hours in the last year.

\section{Univariate Analyses-Completed Training}

For completed training, the univariate analyses included pilots who completed training $(N=7592$ pilots $)$ or were terminated in training $(N=926)$. Pilots who were still in training $(N=1201)$ or on leave $(N=57)$ at the time of data collection were not included in the univariate analyses.

\section{Gender}

No difference existed in completion percentage based on gender.

Age at Date of Hire

The Pearson chi-square showed significant differences in completion percentage based on age at date of hire 


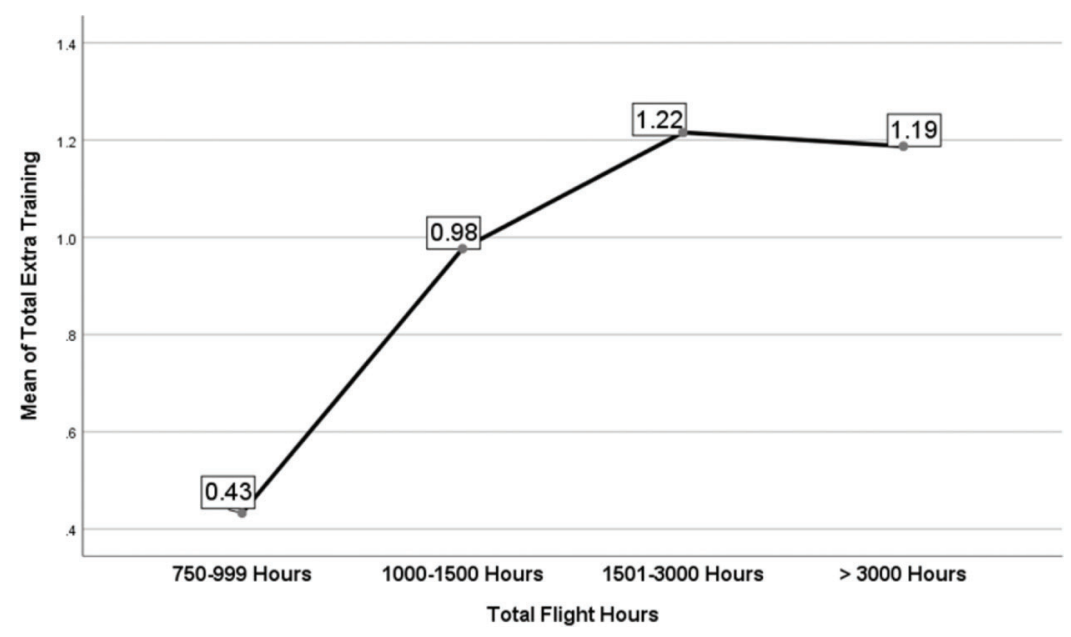

Figure 4. Total extra training events based on total flight hours.

$\left(N=8497 ; \chi^{2}(3)=563.46, p<0.00\right)$. Pilots whose age at date of hire was 21-25 had a significantly higher completion percentage $(96.3 \%)$; pilots whose age at date of hire was 26-31 also had a significantly higher completion percentage $(95.0 \%)$.

\section{Highest Level of Degree}

The Pearson chi-square showed significant differences in completion percentage for highest level of degree $\left(N=8374 ; \chi^{2}(4)=73.47, p<0.00\right)$. Pilots with a bachelor's degree had a significantly higher completion percentage $(91.1 \%)$; pilots with a doctoral degree had a significantly lower completion percentage (69.8\%).

\section{AABI-Accredited Flight Degree Program Graduate}

The Pearson chi-square showed significant differences in completion percentage for AABI-accredited flight degree program graduates $\left(N=6891 ; \chi^{2}(1)=31.92, p<0.00\right)$. AABI-accredited flight degree program graduates had a significantly higher completion percentage (93.4\%).

\section{Aviation Graduate}

The Pearson chi-square showed significant differences in completion percentage for aviation graduates $(N=6857$; $\left.\chi^{2}(1)=18.93, p<0.00\right)$. Aviation graduates had a significantly higher completion percentage $(90.9 \%)$.

\section{Undergraduate GPA}

The one-way ANOVA showed significant differences in completion percentage based on undergraduate GPA $(N=3918 ; F(1,3916)=13.52, p<0.00)$. Pilots with an undergraduate GPA of 3.3-3.8 had a significantly higher completion percentage (92\%); pilots with an undergraduate GPA greater than 3.8 also had a significantly higher completion percentage $(91 \%)$.

\section{Years between Graduation and Hire}

The Pearson chi-square showed significant differences in completion percentage based on years between graduation and hire $\left(N=6557 ; \chi^{2}(8)=492.92, p<0.00\right)$. Table 6 shows the years between graduation and hire with significant completion percentages.

Table 6

Completion percentage based on years between graduation and hire.

\begin{tabular}{lc}
\hline Years between graduation and hire & Completion percentage \\
\hline $0-5$ years (significantly higher) & $94.6 \%$ \\
$6-10$ years (significantly higher) & $92.0 \%$ \\
$11-15$ years & $88.2 \%$ \\
$16-20$ years & $81.1 \%$ \\
$21-25$ years & $77.3 \%$ \\
$26-30$ years & $72.0 \%$ \\
$31-35$ years (significantly lower) & $55.7 \%$ \\
$36-40$ years (significantly lower) & $50.0 \%$ \\
$41-45$ years (significantly lower) & $50.0 \%$ \\
\hline
\end{tabular}

\section{Flight Instructor}

The Pearson chi-square showed significant differences in completion percentage for pilots with Flight Instructor certificates $\left(N=7607 ; \chi^{2}(1)=20.11, p<0.00\right)$. Pilots with Flight Instructor certificates had a significantly higher completion percentage $(91 \%)$.

\section{Military Pilot}

No difference existed in completion percentage for former military pilots. 


\section{Rotor/Helicopter Pilot}

No difference existed in completion percentage for former rotor/helicopter pilots.

\section{Predominant Employment}

The Pearson chi-square showed significant differences in completion percentage based on predominant employment $\left(N=8313 ; \chi^{2}(7)=97.66, p<0.00\right)$. Pilots whose predominant employment was non-aviation had a significantly lower completion percentage (77\%).

\section{Reported Failed FAA Check-Rides}

The Pearson chi-square showed significant differences in completion percentage for pilots with reported failed FAA check-rides $\left(N=6530 ; \chi^{2}(3)=7.95, p<0.05\right)$. Pilots with zero reported failed FAA check-rides had a significantly higher completion percentage (90.4\%). Pilots with one reported failed FAA check-ride also had a significantly higher completion percentage $(90.1 \%)$. Pilots with two reported failed FAA check-rides also had a significantly higher completion percentage (90.0\%).

Type ATP

The Pearson chi-square showed significant differences in completion percentage based on type ATP $(N=8414$; $\left.\chi^{2}(3)=105.53, p<0.00\right)$. Pilots with a Military R-ATP (750 hours) had a significantly higher completion percentage $(91.5 \%)$. Pilots with an Institutional Authority R-ATP (1,000 hours or 1,250 hours) also had a significantly even higher completion percentage $(95.4 \%)$.

\section{Total Flight Hours}

The Pearson chi-square showed significant differences in completion percentage based on total flight hours $(N=$ 8498; $\left.\chi^{2}(3)=167.72, p<0.00\right)$. Pilots with 750-999 total flight hours had a significantly higher completion percentage (95.7\%); pilots with 1,000-1,500 total flight hours had a significantly higher completion percentage (94.0\%).

\section{Recency Hours-Last 6 Months}

The Pearson chi-square showed significant differences in completion percentage based on recency hours in the last 6 months $\left(N=1541 ; \chi^{2}(1)=25.31, p<0.00\right)$. Pilots with more than the mean (497 hours) recency hours in the last 6 months had a significantly higher completion percentage (91.3\%).

\section{Recency Hours-Last Year}

The Pearson chi-square showed significant differences in completion percentage based on recency hours in the last year $\left(N=2097 ; \chi^{2}(1)=15.62, p<0.00\right)$. Pilots with more than the mean (475 hours) recency hours in the last year had a significantly higher completion percentage (90.0\%).

\section{Univariate Analyses-Extended IOE}

Pilots with IOE hours are included in the analyses. Many of the Background variables showed no significant difference in extended IOE: gender, age at date of hire, highest level of degree, aviation graduate, undergraduate GPA, years between graduation and hire, flight instructor, former rotor/helicopter pilot, predominant employment, type ATP, total flight hours, and recency hours in the last 6 months.

\section{AABI-Accredited Flight Degree Program Graduate}

The one-way ANOVA showed significant differences in extended IOE for AABI-accredited flight degree program graduates $(N=6184 ; F(1,6182)=6.72, p=0.010)$. AABI-accredited flight degree program graduates required significantly less extended IOE (average IOE Z-score = $-0.054)$.

\section{Military Pilot}

The one-way ANOVA showed significant differences in extended IOE for former military pilots $(N=7562 ; F(1$, $7560)=4.91, p=0.027)$. Former military pilots required significantly less extended IOE (average IOE Z-score = $-0.053)$.

\section{Reported Failed FAA Check-Rides}

The one-way ANOVA showed significant differences in extended IOE for pilots with reported failed FAA checkrides $(N=5864 ; F(3,5860)=8.59, p<0.00)$. Figure 5 shows increasing average IOE $Z$-scores as the number of reported failed FAA check-rides increased. Each value of reported failed FAA check-rides (none, 1, 2, and 3 or more) was statistically significantly different from the other values.

\section{Recency Hours-Last Year}

The one-way ANOVA showed significant differences in extended IOE based on recency hours in the last year $(N=$ $1817 ; F(1,1815)=4.21, p=0.040)$. Pilots with more than the mean (475 hours) recency hours in the last year required significantly less extended IOE (average IOE Z-score = $-0.056)$.

\section{Summary of Univariate Analyses}

The highest criteria for success were: $\geqslant 90 \%$ completions and $\leq 1$ extra training event. In rank order, the following 


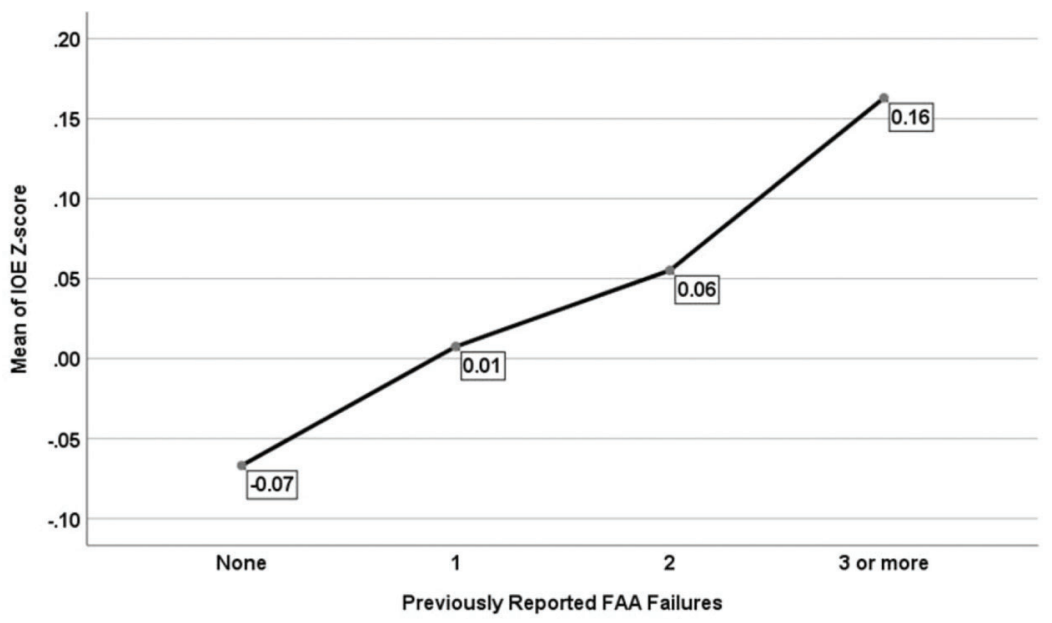

Figure 5. Average IOE Z-score based on number of reported failed FAA check-rides.

pilots were most successful in regional airline initial training:

1. Pilots who had an undergraduate GPA of 3.3 or higher.

2. Pilots who graduated from college within five years of their hire date.

3. Pilots who had either a Military R-ATP (750 hours) or an Institutional Authority R-ATP (1,000 hours or 1,250 hours).

4. Pilots who graduated from an AABI-accredited flight degree program.

5. Pilots who had 1,500 or fewer total flight hours.

6. Pilots who had a bachelor's degree.

\section{Multivariate Analyses}

The multivariate analyses were completed using a ChiSquare Automatic Interaction Detector (CHAID) tree diagram. CHAID is the oldest decision tree classification method and is similar to regression analyses, cluster analyses, and discriminant analyses. CHAID is based on adjusted Bonferroni significance testing that, “...uses builtin significance testing with the consequence of using the most significant predictor (rather than the most explanatory), multi-way splits (in contrast to binary) and a new type of predictor which is especially useful in handling missing information" (Kass, 1980, p. 119). Typically, CHAID is used for prediction, classification, and detection of interaction between variables.

The sample used for multivariate analyses included pilots who completed training $(N=7592$ pilots $)$ or were terminated in training $(N=926)$. Pilots who were still in training $(N=1201)$ or on leave $(N=57)$ at the time of data collection were not included. Three Performance variables were individually evaluated: completed training, zero through two total extra training events, and normal IOE $Z$-scores. The normal IOE $Z$-scores category included
IOE $Z$-scores less than or equal to one standard deviation above the mean.

\section{Multivariate Analysis of Completed Training}

Overall, $89 \%$ of the pilots completed training (Figure 6). The probability for completed training increased to 91$97 \%$ for pilots younger than 35 years old at the date of hire. The probability for completed training increased to 90-95\% for pilots who graduated from college/university within 14 years of their date of hire. The probability for completed training increased to $92-96 \%$ for pilots with total hours less than 1,502 hours.

\section{Multivariate Analysis of Zero through Two Total Extra Training Events}

Overall, $77 \%$ of the pilots had zero through two total extra training events (Figure 7). The probability for zero through two total extra training events increased to $78-82 \%$ for pilots who graduated from college/university between 1.1 and 7 years before their date of hire. The probability for zero through two total extra training events increased to $82-87 \%$ for pilots who had an undergraduate GPA between 3.61 and 3.75. The probability for zero through two total extra training events increased to $85 \%$ for pilots with Flight Instructor certificates.

\section{Multivariate Analysis of Normal IOE Z-Scores}

Overall, $87 \%$ of the pilots had normal IOE Z-scores (Figure 8). The probability of a normal IOE Z-score increased to $89 \%$ if the pilot had an undergraduate GPA greater than 2.8. The probability of a normal IOE Z-score increased to $89 \%$ for pilots with zero previous FAA checkride failures. The probability of a normal IOE Z-score increased to $88 \%$ for pilots younger than 48 years old at the date of hire. 


\begin{tabular}{|c|c|}
\hline \multirow{9}{*}{$\begin{array}{l}\text { Variables } \\
\text { Included }\end{array}$} & Age at Date of Hire \\
\hline & $\begin{array}{l}\text { Yrs Between Grad \& } \\
\text { Date of Hire }\end{array}$ \\
\hline & Undergraduate GPA \\
\hline & AABI Flight Degree? \\
\hline & Aviation Degree? \\
\hline & Flight Instructor? \\
\hline & Military Pilot? \\
\hline & \# Previous FAA Failures \\
\hline & Total Hours \\
\hline
\end{tabular}

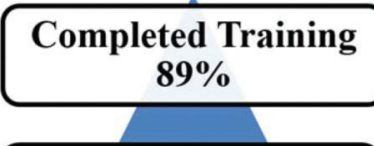

1. Age at Date of Hire

Younger than 35 years $\chi^{2}=703.7|d f=5| p<.000$

2. Years between Grad \& Hire 14 or Fewer Years

$\chi^{2}=409.7|d f=4| p<.000$

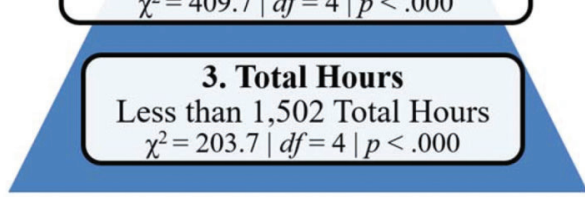

Figure 6. Best predictors for completing training.

\begin{tabular}{ll}
\hline $\begin{array}{l}\text { Variables } \\
\text { Included }\end{array}$ & Age at Date of Hire \\
\cline { 2 - 2 } & $\begin{array}{l}\text { Yrs Between Grad \& } \\
\text { Date of Hire }\end{array}$ \\
& Undergraduate GPA \\
\hline AABI Flight Degree? \\
\hline Aviation Degree? \\
Flight Instructor? \\
Military Pilot? \\
\# Previous FAA Failures \\
Total Hours
\end{tabular}

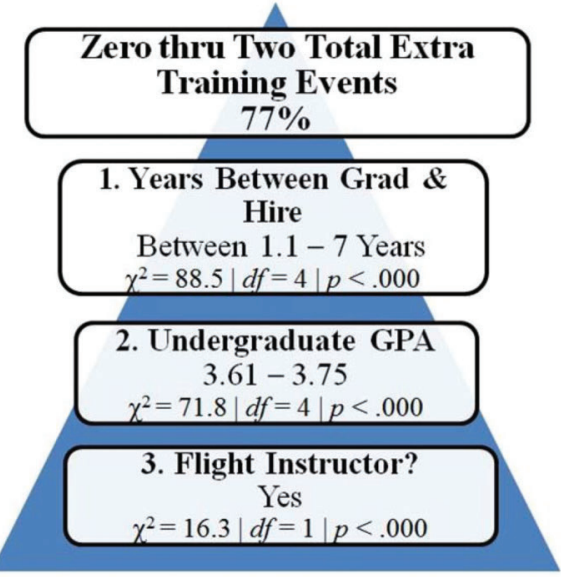

Figure 7. Best predictors for zero, one, or two total extra training events.

\begin{tabular}{|c|c|}
\hline \multirow{9}{*}{$\begin{array}{l}\text { Variables } \\
\text { Included }\end{array}$} & Age at Date of Hire \\
\hline & $\begin{array}{l}\text { Yrs Between Grad \& } \\
\text { Date of Hire }\end{array}$ \\
\hline & Undergraduate GPA \\
\hline & AABI Flight Degree? \\
\hline & Aviation Degree? \\
\hline & Flight Instructor? \\
\hline & Military Pilot? \\
\hline & $\begin{array}{l}\text { \# Previous FAA } \\
\text { Failures }\end{array}$ \\
\hline & Total Hours \\
\hline
\end{tabular}

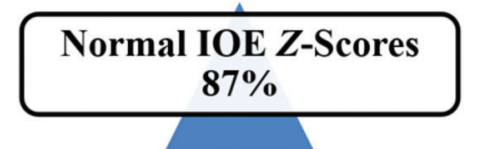

1. Undergraduate GPA

Greater than 2.8

$\chi^{2}=20.0|d f=1| p<.000$

7

2. \# Previous FAA Failures

Zero Failures

$\chi^{2}=23.6|d f=2| p<.000$

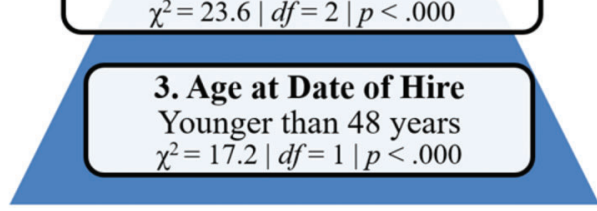

Figure 8. Best predictors for normal IOE Z-scores.

\section{Summary of the Multivariate Analyses}

The multivariate analyses found six unique Background variables to be significant for the Performance variables of completed training, Zero through Two total extra training events, and normal IOE Z-scores: age at date of hire, years between graduation and hire, total hours, undergraduate GPA, FAA previous failures, and flight instructor. Three of 
these six unique Background variables (years between graduation and hire, undergraduate GPA, and age at date of hire) had different CHAID thresholds based on the Performance variable and appear twice in the list below. The significant Background variables, in order from the strongest to the weakest, are:

1. Age at date of hire: younger than 35 [completed training]

2. Years between graduation and hire: 14 or fewer years [completed training]

3. Total hours: less than 1,502 hours [completed training]

4. Years between graduation and hire: $1.1-7$ years [zero through two total extra training events]

5. Undergraduate GPA: 3.61-3.75 [zero through two total extra training events]

6. FAA previous failures: zero [normal IOE $Z$-scores]

7. Undergraduate GPA: greater than 2.8 [normal IOE $Z$-scores]

8. Age at date of hire: younger than 48 years [normal IOE Z-scores]

9. Flight instructor: yes [zero through two total extra training events].

\section{Comparison of PSS 2015 and PSS 2018}

Descriptive Statistics Comparison (2015 vs. 2018)

The 2015 PSS data were collected from nineteen Part 121 airlines from April to October 2015, yielding 6,734 records. These data were collected between 21 and 27 months after the effective date of the FOQ Rule-August 1, 2013 (FAA, 2013). When the results of the 2015 PSS were published, several reviewers commented that the data collection was too soon-before the US regional airlines were fully operational with the FOQ Rule.

The 2018 PSS data were collected from five Part 121 airlines from September to November 2018, yielding 9,776 records. One-third more pilots were hired by only five airlines in comparison to the population study in 2015. These 2018 PSS pilots were hired two to five years since the FOQ Rule (FAA, 2013) went into effect, and the airlines were fully operational with the FOQ Rule.

The comparisons that follow display the notable differences among the new-hire pilots Background and Performance variables. Table 7 displays the comparison of the important descriptive statistics of Background variables (independent variables) between the 2015 PSS and the 2018 PSS. Table 8 displays the comparison of the important descriptive statistics of Performance variables (dependent variables) between the 2015 PSS and the 2018 PSS.

Table 8

Descriptive statistics of performance variables between PSS 2015 and PSS 2018.

\begin{tabular}{lcc}
\hline $\begin{array}{l}\text { Performance } \text { variables } \\
\text { (dependent variables) }\end{array}$ & PSS 2015 & PSS 2018 \\
\hline Did not complete training & $11 \%$ & $11 \%$ \\
Required extra training & $38 \%$ & $45 \%$ \\
$\begin{array}{l}\text { Average number of total extra } \\
\text { training events }\end{array}$ & 0.98 & 1.20 \\
Required extended IOE & $12 \%$ & $13 \%$ \\
\hline
\end{tabular}

Performance Comparison (2015 vs. 2018)

Table 9 compares the performance of pilots, based on their Backgrounds, between the 2015 PSS and the 2018 PSS results. For completed training, the variables GPA, flight instructor, and zero failed check-rides were statistically significant in 2018 but were not statistically significant in 2015. For total extra training events, the variables GPA, rotor/helicopter pilot were statistically significant in 2018 but were not statistically significant in 2015. Age was not collected in 2015. The 2015 results were reported differently from the 2018 results; therefore, only qualitative

Table 7

Descriptive statistics of background variables between PSS 2015 and PSS 2018.

\begin{tabular}{|c|c|c|}
\hline Background variables (independent variables) & PSS 2015 & PSS 2018 \\
\hline Gender $=$ female & No gender data & $5.6 \%$ \\
\hline Age at date of hire & Median $=27$ & Median $=31$ \\
\hline Bachelor's degree & $63 \%$ & $60.6 \%$ \\
\hline AABI-accredited flight degree program graduate & $23 \%$ & $22 \%$ \\
\hline Aviation graduate & $51 \%$ & $51 \%$ \\
\hline Undergraduate GPA & Median $=3.4$ & Median $=3.4$ \\
\hline Years between graduation and hire & Median $=6$ & Median $=5$ \\
\hline Flight instructor $=$ Yes & $78 \%$ & $72 \%$ \\
\hline Military pilot & $12 \%$ & $20 \%$ \\
\hline Rotor/helicopter pilot & No helicopter data & $8 \%$ \\
\hline Predominant employment & Airline $=34 \%$ & Airline $=29 \%$ \\
\hline Previously reported failed FAA check-rides & One $=54 \%$ & One $=60 \%$ \\
\hline Traditional ATP certificate & $83 \%$ & $67 \%$ \\
\hline 1,500 or fewer total flight hours & $27 \%$ & $39 \%$ \\
\hline Recency hours-last six months & No recency data & Median $=500$ \\
\hline
\end{tabular}


Table 9

Comparison of completed training and total extra training events based on background variables between PSS 2015 and PSS 2018.

\begin{tabular}{|c|c|c|c|c|}
\hline \multirow[b]{2}{*}{ Background variable } & \multicolumn{2}{|c|}{ Completed training } & \multicolumn{2}{|c|}{ Total extra training events } \\
\hline & 2015 & 2018 & 2015 & 2018 \\
\hline Age $\leq 31$ & N/A & Sig. $(96 \%)$ & N/A & Sig. (1.03) \\
\hline Bachelor's degree & Sig. (more) & Sig. $(91 \%)$ & Sig. (fewer) & Sig. (1.00) \\
\hline AABI-accredited flight degree program graduate & Sig. (more) & Sig. $(93 \%)$ & Sig. (fewer) & Sig. (0.89) \\
\hline Aviation graduate & Sig. (more) & Sig. $(91 \%)$ & Sig. (fewer) & Not Sig. \\
\hline GPA $>3.3$ & Not sig. & Sig. $(92 \%)$ & Not sig. & Sig. $(0.81)$ \\
\hline $0-5$ years between graduation and hire & Sig. (more) & Sig. $(95 \%)$ & Sig. (fewer) & Sig. (0.87) \\
\hline Flight instructor $=$ yes & Not Sig. & Sig. $(91 \%)$ & Not Sig. & Not Sig. \\
\hline Military pilot & Sig. (more) & Not sig. & Sig. (fewer) & Sig. (0.89) \\
\hline Rotor/helicopter pilot & No data & Not sig. & No data & Sig. (0.93) \\
\hline Previous employment_-Part 121 & Sig. (more) & Not sig. & Sig. (fewer) & Sig. (0.86) \\
\hline Zero failed FAA check-rides & Not sig. & Sig. $(91 \%)$ & Not sig. & Not sig. \\
\hline Institutional Authority R-ATP (1,000 hours or 1,250 hours) & Sig. (more) & Sig. $(95 \%)$ & Sig. (fewer) & Sig. $(0.90)$ \\
\hline Flight hours $(1,500$ hours or fewer $)$ & Sig. (more) & Sig. $(94 \%)$ & Sig. (fewer) & Sig. (0.98) \\
\hline
\end{tabular}

Note. Sig. means a statistically significant difference existed. Not sig. means no statistically significant differences existed. N/A means not available.

descriptors (more, fewer) were available for the 2015 results. For the 2018 results, the percentage of pilots completing training and the number of total extra training events required are displayed.

\section{Conclusions}

The PSS series results continue to be consistent with the 2010 ANPRM statement: "The FAA believes that, although the flight hours required to qualify for an ATP certificate can benefit pilots, experience is not measured in flight time alone. Other factors, such as certain types of academic training, practical training/experience, and experience in a crew environment, are also important" (FAA, 2010, para. 3). For the 2018 PSS, the factors that were found to be significant in the univariate and/or multivariate analyses were:

- Having an undergraduate GPA of 3.3 or higher.

- Being less than 35 years old at the date of hire.

- Having 14 or fewer years between graduation and hire.

- Qualifying as Military R-ATP (750 hours) or Institutional Authority R-ATP (1,000 hours or 1,250 hours).

- Graduating from an AABI-accredited flight degree program.

- Having 1,502 or fewer total flight hours.

- Completing a bachelor's degree.

- Having zero previous FAA check-ride failures.

- Holding a Flight Instructor certificate.

Pilots with the highest criteria for success ( $\geqslant 90 \%$ completions and $\leq 1$ extra training event) have the Background variables that could be characterized as younger pilots who recently completed a structured collegiate degree program that required academic excellence to maintain a higher GPA. These pilots likely trained on electronic flight instrument systems (glass-cockpit) avionics suites; successfully demonstrated their abilities during critical check-rides; and taught/modeled flight skills to other pilots-in-training. These characteristics also highlight the importance of disciplined flight experiences and the non-technical crew resource management skills.

\section{Acknowledgments}

Sincere thanks to the 2018 Pilot Source Study sponsors - AABI Collaborative Research Committee - College of Aviation-Embry-Riddle (Daytona) • College of AviationEmbry-Riddle (Prescott) • Endeavor Air • Envoy Air

- Mountain Air Cargo - Regional Airline Association - Ypsilon Associates.

\section{References}

Airline Safety and Federal Aviation Administration Extension Act of 2010. (2010). Public Law 111-216,124 Stat, 2348.

Aviation Accreditation Board International. (2019, July 19). Accreditation criteria manual: Form 201. Retrieved from http://www.aabi.aero/ about-aabi/forms-and-publications/

Bjerke, E., Smith, G., Smith, M., Christensen, C., Carney, T., Craig, P., \& Niemczyk, M. (2016). Pilot source study 2015: US regional airline pilot hiring background characteristic changes consequent to Public Law 111-216 and the FAA first officer qualifications rule. Journal of Aviation Technology and Engineering, 5(2), 3-14.

Brady, T. (2015). The impact on educational technology of a fatal airline accident: A case study. International Journal of Information and Learning Technology, 32(3), 174.

Federal Aviation Administration. (2010, February 8). New pilot certification requirements for air carrier operations (ANPRM, Docket no. FAA-2010-0100; Notice no. 10-02). Washington, DC: Department of Transportation.

Federal Aviation Administration. (2013, July 15). Pilot certification and qualification requirements for air carrier operations; Final rule (Docket no. FAA-2010-0100; Amdt. nos. 61-130; 121-365; 135-127; 141-1; 142-9). Washington, DC: Department of Transportation.

Federal Aviation Administration. (2017). Advanced qualification program (AC 120-54A). Washington, DC: AFS-200. Retrieved from 
https://www.faa.gov/documentLibrary/media/Advisory_Circular/AC 120-54A_CHG_1.pdf

Kass, G. V. (1980). An exploratory technique for investigating large quantities of categorical data. Applied Statistics, 29(2), 119-127.

Lutte, B. (2018). Pilot supply at the regional airlines: Airline response to the changing environment and the impact on pilot hiring. Journal of Aviation/Aerospace Education \& Research, 27(1), 1-22. http://dx.doi. org/10.15394/JAAER.2018.1749

National Transportation Safety Board. (2010). Loss of control on approach, Colgan Air, Inc., operating as Continental Connection Flight 3407, Bombardier DHC-8-400, N200WQ, Clarence Center, New York, February 12, 2009. NTSB/AAR-10/01. Washington, DC: National Transportation Safety Board.

Operating Requirements: Domestic, Flag, and Supplemental Operations Rule, 14 CFR $\$ 121$ (2015).

Regional Airline Association. (2019). The 2019 RAA annual report. Retrieved December 3, 2019, from https://www.raa.org/content-hub/ raa-annual-reports/raa-2019-annual-report/

Shane, N. (2016). The relationship of a pilot's educational background, aeronautical experience and recency of experience to performance in initial training at a regional airline. Theses and Dissertations, 343 Retrieved April 14, 2019, from https://commons.und.edu/theses/343
Smith, G., Bjerke, E., Smith, M., Christensen, C., Carney, T., Craig, P., \& Niemczyk, M. (2016). Pilot source study 2015: An analysis of FAR Part 121 pilots hired after Public Law 111-216-Their backgrounds and subsequent successes in US regional airline training and operating experience. Journal of Aviation Technology and Engineering, 6(1), 64-89.

Smith, G. M., Herchko, D., Bjerke, E., Niemczyk, M., Nullmeyer, R., Paasch, J., \& NewMyer, D. A. (2013). The 2012 pilot source study (Phase III): Response to the pilot certification and qualification requirements for air carrier operations. Journal of Aviation Technology and Engineering, 2(2), 13-23.

Smith, G. M., NewMyer, D. A., Bjerke, E., Niemczyk, M., \& Hamilton, R. A. (2010). Pilot source study: An analysis of pilot backgrounds and subsequent success in US regional airline training programs. International Journal of Applied Aviation Studies, 10(1), 73-96.

Smith, M. O., Smith, G. M., Bjerke, E., Christensen, C., Carney, T. Q., Craig, P. A., \& Niemczyk, M. (2017). Pilot source study 2015: A comparison of performance at Part 121 regional airlines between pilots hired before the U.S. Congress passed Public Law 111-216 and pilots hired after the law's effective date. Journal of Aviation Technology and Engineering, 6(2), 50-79. 